\title{
Behavior of Dairy Cows in an Alternative Bedded-Pack Housing System
}

\author{
M. I. Endres ${ }^{1}$ and A. E. Barberg \\ Department of Animal Science, University of Minnesota, St. Paul 55108
}

\begin{abstract}
The objectives of this study were to measure lying behavior and social interactions of lactating cows housed in an alternative bedded-pack system, commonly referred to as a compost dairy barn, and to investigate the association between the temperature-humidity index and lying behavior of these cows. The study was conducted in 12 compost dairy barns in Minnesota between late June 2005 and September 2005. Lying, standing, and walking behavior of 147 focal cows was measured by automatic activity monitors. The daily lying time was $9.34 \pm 1.94 \mathrm{~h}$. The number of daily lying bouts was $11.0 \pm 3.2$ and the lying bout length was 50.8 $\pm 35.6 \mathrm{~min}$. As days in milk increased, the total number of lying bouts increased, corresponding to an increase in total daily lying time. Cows in the compost barns lay down for less time, took more steps, and reduced the length of lying bouts as the temperature-humidity index increased. Social interactions and lying positions of all cows in the bedded-pack area (total of 886 cows in the 12 dairies) were recorded using visual observations during two 4-h periods on 2 separate days. A total of $43.3 \%$ of the cows were lying down at any time. All 4 natural lying positions (head back, head up, flat on the side, and head on the ground) were observed in 9 of the bedded packs during the direct visual observation periods. The majority ( $84.6 \%$ ) of the cows observed lying down assumed the head-up position. Of all observed lying events, the head-back lying position was assumed $8.8 \%$ of the time, the head on the ground $5.4 \%$ of the time, and flat on the side $0.8 \%$ of the time. Observations of social interactions on the bedded-pack area showed that $0.94 \pm 1.5$ incidents of chasing away, $0.94 \pm 1.8$ of pushing, $1.4 \pm 1.6$ of head butting, and $2.3 \pm 2.9$ of allogrooming (social licking) occurred per hour. Observations of lying behavior, social interactions, and natural lying positions indicated that compost dairy barns can be an adequate housing system for dairy cows.
\end{abstract}

Key words: lying behavior, bedded pack, temperaturehumidity index

Received November 11, 2006.

Accepted May 8, 2007.

${ }^{1}$ Corresponding author: miendres@umn.edu

\section{INTRODUCTION}

Compost dairy barns are an alternative loose-housing system with a large bedded-pack (resting) area separated from a feed alley by a $1.2-\mathrm{m}$-high concrete wall. Unlike in conventional bedded-pack systems, the bedding material (predominantly dry, fine wood shavings or sawdust) is aerated twice daily with cultivator-type equipment to dry the surface and incorporate manure into the pack. Previously, we reported that the main reasons mentioned by the dairy producers for building this type of housing system were for improved cow comfort, cow longevity, and ease of completing daily chores (Barberg et al., 2007).

Loose-housing systems such as compost barns should allow cattle freedom of movement. The ability and freedom to lie down and rest at ease are important for dairy cattle welfare. Dairy cattle spend 8 to $16 \mathrm{~h} / \mathrm{d}$ lying down, which emphasizes the importance of the lying surface to the animal (Haley et al., 2001). Lying time is a measurable and usable indicator of animal welfare (Fregonesi and Leaver, 2001).

Cattle movements of lying down and getting up are affected by their physical environment, such as the lying surface and stall dimensions. Increased lying times were observed when softer lying surfaces were available, particularly when large amounts of bedding were used (Krohn and Munksgaard, 1993). The number of times a cow stands up and lies down each day (i.e., the number of lying bouts) and the duration of each lying bout may be used to measure the comfort of the lying surface and housing system. Cows housed in sand-bedded free stalls had a significantly greater proportion of long lying bouts ( $>60 \mathrm{~min}$ ) than did cows in mattressbedded free stalls (Cook et al., 2004).

Type of housing can allow or hinder natural behavior. Four common lying positions are assumed by cattle: flat on the side, head back, head on the ground, and head up, the most common position (Krohn and Munksgaard, 1993). The type of housing system influences the lying position that a cow assumes. Cows spent more time lying with their heads resting on the ground or with their heads back when they were housed on pasture than in tie-stall barns (Ketelaar-de Lauwere et al., 1999), regardless of the bedding material (Haley et al., 2001). 
The social structure of dairy cattle can be described as a series of dominance relationships and social bonds characterized by agonistic (aggressive) and positive social interactions. Several farm conditions contribute to and affect the social behavior of a dairy herd, including the type of housing, the number of cows, and the space allowance per cow (Menke et al., 1999). Allogrooming (social licking) is a positive social interaction that causes a calming effect between cows, reducing the amount of social tension and stabilizing dominant and subordinate relationships in a herd. Agonistic interactions between cattle are composed of pushes, threats, head butts, chasing, and avoidance. Most displacements, head butts or pushing, are a result of competition for resources, such as feed or water, space at the feed bunk, or resting space.

Weather, mainly temperature and humidity, or the temperature-humidity index (THI), has an impact on lying time. The THI has been used to estimate the level of heat stress in dairy cattle. Arnold and Dudzinski (1978) reported that as humidity increased, cattle had a greater level of stress when the temperature increased above $28^{\circ} \mathrm{C}$. Overton et al. (2002) found that high environmental temperatures had a negative impact on the proportion of eligible cows observed lying.

The objectives of this study were to measure lying behavior and observe social interactions of lactating cows housed in compost dairy barns. Additionally, we investigated the association between THI and lying behavior of cows housed in compost dairy barns.

\section{MATERIALS AND METHODS}

\section{Farms}

We studied 12 dairies in Minnesota that used compost bedded-pack barns for housing lactating cows. The study was conducted between late June and September 2005. Each farm was visited twice, 1 wk apart, to collect on-farm data. The experimental protocol of this study was approved by the Institutional Animal Care and Use Committee of the University of Minnesota.

Individual herds were selected on the basis of the producers having used the alternative housing system for their milking herd for at least 6 mo prior to our visit. Dairy producers using this housing system were identified by extension educators. Following the identification of all the compost barn herds in the state, letters of invitation were sent to the 12 producers identified to confirm whether they met the study criteria of occupancy date and use of the barn for their entire milking herd. The dairies represented approximately $92 \%$ of all Minnesota dairies with this system that met the study criteria. One dairy had had cows housed in this system since fall 2001, 5 since fall 2003, and 5 since fall 2004 .
Only 1 dairy had been using this system for 6 mo at the time of the visit. Dairy herd records for the time of the visit were obtained from the DHIA for 11 of the dairies. Days in milk for the herd not using DHIA recording were calculated from on-farm records.

\section{Measurement of Behavior}

Lying, standing, and walking behavior was measured with automatic activity monitors (IceTag, IceRobotics, Roslin, UK), which were validated for use in dairy cattle by Munksgaard et al. (2006). Automatic monitoring of lying, standing, and walking behavior was performed for approximately $1 \mathrm{wk}$ in each herd. The monitors had a tough plastic housing designed to withstand the farm environment and a simple strap mechanism for easy attachment and removal from the rear leg of the cows. IceTags are activity monitors that use an electronic accelerometer to automatically determine the percentage of time spent standing, lying, and active. The behavior referred to as "active" was measured when a cow moved her leg but was not necessarily taking a step. This type of behavior could be registered when a cow was restless or being pushed around among a group of animals. The monitors log data 8 times/s, and algorithms are used to generate the average percentage of time allocated to each of the behaviors.

For our analysis, data were downloaded from the monitors on a per-minute basis with the IceTagAnalyser software (IceRobotics) and were exported to an Excel spreadsheet (Microsoft Corp., Redmond, WA). Data downloaded from on-board memory included percentage of time spent lying, standing, or active, and number of steps taken by each cow. The data were converted to minutes per hour and minutes per day by using the actual percentage of the behavior (e.g., percentage of lying) within the minute or hour. Number of lying bouts per day and per hour were determined as the mean number of times a cow stood up and lay down in a period of $24 \mathrm{~h}$ or $60 \mathrm{~min}$, respectively. Lying bouts of $<2$ min were discarded by recommendation of the manufacturer as possibly being incidences when the cow lifted the leg on which the IceTag was attached. Lying bouts of $<2$ min occurred $<1.5 \%$ of the time. We caution that in approximately $10.4 \%$ of per-minute data downloaded from the monitors, "active" was recorded at the same time as lying was recorded. This happened either during the minute immediately preceding or following a lying bout, which would reflect the transition between lying and standing ( $4.4 \%$ of the data), or during a lying bout (6\% of the data), which could result in an underestimation of lying time. Yet the latter error should be minimal, because in the instances when "ac- 
tive" was recorded during a lying bout, the percentage of lying per minute was generally $>90 \%$ instead of $100 \%$.

The activity monitors were placed on the rear leg of a minimum of $15 \%$ of the cows in each herd. These cows were selected as focal animals to represent the entire herd. A random sample of cows of each parity group (first, second, third, and >third lactation) and stage of lactation was used in each of the 12 herds. Cows $<30$ DIM or $>305$ DIM at the time of visit were not included in the selection process. Cows exhibiting health problems or having a locomotion score of $>3$ (on a 1 to 5 scale, where 1 = normal locomotion, $2=$ imperfect locomotion, 3 = lame, $4=$ moderately to severely lame, and 5 = severely lame; Sprecher et al., 1997) were excluded.

\section{Lying Positions and Social Interactions}

Cow lying positions were recorded every 15 min by visual scan observations during a 4-h period on both days of on-farm data collection, for a total of $8 \mathrm{~h}$ for each farm. Data included all lactating cows present in the bedded-pack area during those periods, but not cows in the feed alley, and observations took place at the same time of day on both days (starting at approximately $2 \mathrm{~h}$ after the morning milking). Cows were observed from a perched point above the pack area. Data recorded were the percentage of cows adopting specific lying positions recognized as natural ones: flat on the side, head back, head on the ground, and head up (Krohn and Munksgaard, 1993). Social interactions were continuously monitored and recorded during the same two 4-h time periods. Observations of chasing away (the actor cow coming within $0.5 \mathrm{~m}$ of the reactor cow and causing her to move away, without any physical contact), pushing (hard push from the actor cow against the body of the reactor cow, causing her to move 1 or 2 steps), head butting (fast blow with the head from the actor cow, rather than a hard push, directed at the reactor cow, generally not causing the reactor cow to take steps away from the actor cow), and allogrooming (licking another cow) were recorded and summarized as the number of occurrences per hour for each farm. Threats and avoidance (defined as interactions that would occur at distances between cows greater than $0.5 \mathrm{~m}$, with cows performing specific postures) were not noted because we concluded that it was not possible to record those behaviors accurately. During the observations, there were no interruptions for breeding, injections, or other management tasks.

\section{THI}

The THI of the environment and the barn was documented throughout the sampling week on each farm.
The temperature and relative humidity $(\mathbf{R H})$ were recorded inside each barn by a data logger centrally located in each barn at approximately $2 \mathrm{~m}$ above the pack surface (temperature accuracy, $\pm 0.5^{\circ} \mathrm{C} ; \mathrm{RH}$ accuracy, $\pm 3 \%$; H8 Pro Series, Hobo, Bourne, MA). The outdoor temperature and $\mathrm{RH}$ were obtained from the weather station located closest to each barn (The Weather Channel; www.weather.com). The hourly ambient temperature and $\mathrm{RH}$ inside the barns and from the weather station were used to calculate the THI. The equation used for THI was THI $=\mathrm{td}-(0.55-0.55 \mathrm{RH})(\mathrm{td}-58)$, where td is the dry bulb temperature in degrees Fahrenheit and RH is expressed as a decimal (West et al., 2003). The average hourly THI inside the barn and outdoors were calculated separately for the week between each visit. The hourly THI of the barn was used to determine the association between THI and lying behavior. Nevertheless, on 2 farms, the data loggers inside the barn malfunctioned; therefore, the hourly THI from the weather station was used. The Pearson correlation coefficient for all records of THI for the barn and at the weather station was 0.97 .

\section{Statistical Analysis}

Descriptive statistics (mean, SD, and range) were used to summarize the time spent lying, standing, or active and the number of steps recorded by the automatic monitors (SAS Inst. Inc., Cary, NC). Additionally, descriptive statistics were used to characterize visual observations of social interactions and lying positions. The associations among lying time (minutes per day) and number of lying bouts per day with DIM, parity, and 305-d mature-equivalent milk production at the time of visit were investigated using a mixed-model procedure (PROC MIXED; SAS Inst. Inc.), with cow-day included as a repeated measure with an autoregressive (order 1) covariance structure assumed among records within cow-day. This structure was chosen because it resulted in the best model fit, based on various goodness-of-fit measures, including Akaike's and Bayesian information criteria. Farm and cow within farm were included in the model as random variables. The assumption of random distribution of the residuals was visually evaluated on a residual chart. Analysis was performed as described above, with and without inclusion of the 2 dairies on which cows had access to pasture.

Associations among number of lying bouts per hour, lying time (minutes per hour), duration of lying bouts (minutes), number of steps per hour, and hourly THI and period of the day (night, 2000 to $0800 \mathrm{~h}$; day, 0800 to $2000 \mathrm{~h}$ ) were investigated using a mixed-model procedure (PROC MIXED; SAS Inst. Inc.). The time periods were chosen to ensure that one milking was included 
in each period. Farm, cow within farm, and day were included in the model as random variables. The assumption of random distribution of the residuals was visually evaluated on a residual chart. Analysis was performed as described above, with and without inclusion of the 2 dairies on which cows had access to pasture.

\section{RESULTS AND DISCUSSION}

The herd size for the compost dairy barns was 73.8 \pm 35.3 (mean \pm SD) cows, with a total of 886 cows in 12 dairies. Nine of the herds had only Holstein cows, whereas the other 3 herds included some animals of other breeds, with more than $50 \%$ of the animals being Holsteins. All herds were fed a TMR, with 2 herds providing a TMR in addition to pasture. These 2 herds had constant access to pasture as well as to the compost dairy barn. Cows were fed and milked twice daily. The DHIA rolling herd average was 10,457 $\pm 1,138 \mathrm{~kg}$ (range of 8,321 to $12,411 \mathrm{~kg}$ ), milk fat was $3.69 \pm 0.37 \%$, milk protein was $3.06 \pm 0.15 \%$, and SCC was $325,000 \pm$ 172,000 cells $/ \mathrm{mL}$ for the test date nearest the day of the visit. Additional information about the dairies can be found in a previous publication (Barberg et al., 2007). Table 1 summarizes herd and housing characteristics.

\section{Cow Comfort and Lying Positions}

Compost dairy barns provided good cow comfort. The bedding material was aerated to a depth of 18 to $24 \mathrm{~cm}$ twice daily while cows were away at the parlor, most often with a modified cultivator on a skid loader or small tractor. Typically, no bedding material was removed from the pack area during the year, except in the fall and, in some cases, a layer of 30 to $60 \mathrm{~cm}$ in the spring. The bedded-pack area was cleaned entirely once annually in September or October. A load of clean sawdust was added after removal of the soiled bedding to provide a bedding layer of 30 to $45 \mathrm{~cm}$ to start the new pack. By the end of summer, most packs averaged $120 \mathrm{~cm}$ high. The average resting space for the $12 \mathrm{com}$ post barns was $8.6 \pm 2.6 \mathrm{~m}^{2}$ per cow (Table 1 ).

Ceballos et al. (2004), who used 3-dimensional kinematics to measure the space used by cattle when lying, found that cows use up to $300 \mathrm{~cm}$ of longitudinal space and $180 \%$ of their hip width of lateral space, with an additional $60 \mathrm{~cm}$ of lunging space needed for rising. When lying down, the maximum instantaneous velocity assumed by cows reached nearly $220 \mathrm{~cm} / \mathrm{s}$. Any obstruction (i.e., pipe, board, or wall) that is located within the described area could be hit with great force, subjecting the cow to injury. Compost-bedded packs do not inhibit the size of the lying or lunging space for cows as long as adequate cow density is maintained.

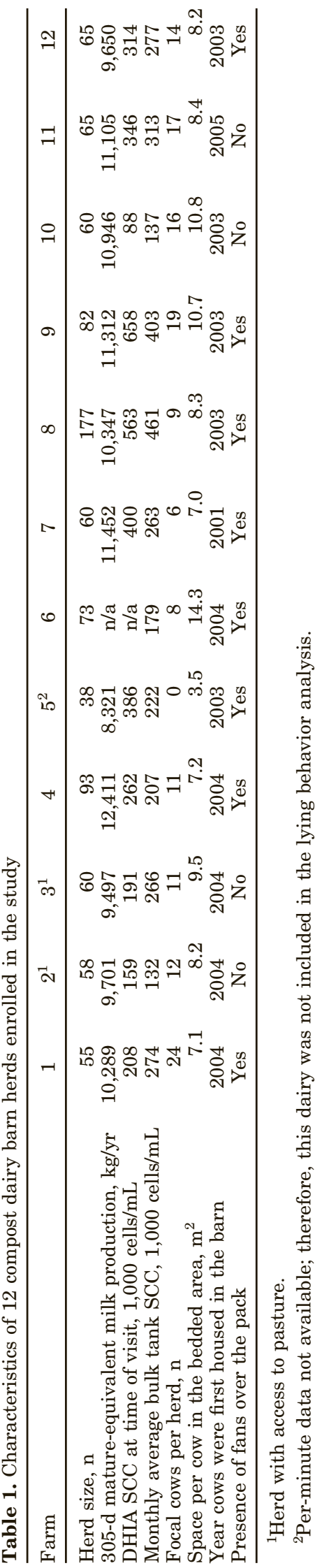

Journal of Dairy Science Vol. 90 No. 9, 2007 
Table 2. Lying behavior of 147 dairy cows housed in compost dairy barns

\begin{tabular}{|c|c|c|c|c|c|c|c|c|c|c|c|}
\hline Farm & 1 & $2^{1}$ & $3^{1}$ & 4 & 6 & 7 & 8 & 9 & 10 & 11 & 12 \\
\hline Average & 9.99 & 10.03 & 8.64 & 11.50 & 10.43 & 10.53 & 12.79 & 12.24 & 10.60 & 11.78 & 12.48 \\
\hline SD & 3.44 & 2.83 & 2.01 & 3.80 & 2.65 & 4.94 & 2.77 & 3.98 & 2.90 & 3.02 & 3.10 \\
\hline Maximum & 19 & 16 & 13 & 24 & 16 & 29 & 22 & 24 & 19 & 19 & 21 \\
\hline \multicolumn{12}{|c|}{ Lying bout duration, $\mathrm{min} /$ bout } \\
\hline Average & 59.84 & 36.91 & 47.45 & 45.22 & 57.61 & 53.37 & 50.92 & 51.80 & 48.75 & 57.10 & 49.80 \\
\hline Maximum & 358 & 137 & 214 & 174 & 156 & 233 & 249 & 190 & 218 & 179 & 277 \\
\hline \multicolumn{12}{|c|}{ Lying time, $\mathrm{h} / \mathrm{d}$} \\
\hline Average & 9.89 & 6.09 & 6.82 & 8.64 & 10.08 & 9.57 & 10.79 & 10.44 & 8.65 & 11.39 & 10.36 \\
\hline SD & 2.66 & 1.64 & 1.51 & 1.73 & 1.83 & 2.39 & 2.01 & 1.92 & 2.21 & 1.91 & 1.55 \\
\hline Minimum & 3.43 & 2.37 & 4.43 & 4.32 & 5.80 & 3.58 & 6.72 & 4.45 & 2.90 & 6.48 & 6.75 \\
\hline Maximum & 16.80 & 9.72 & 9.98 & 12.10 & 13.12 & 12.38 & 15.42 & 14.90 & 13.23 & 14.68 & 16.07 \\
\hline
\end{tabular}

${ }^{1}$ Herd with access to pasture.

Cows were able to assume all the natural lying positions without obstruction in most of the barns. A total of 410 lying position observations were recorded in the 12 compost barns. A total of $43.3 \pm 28.5 \%$ of the cows on the bedded pack were lying during the direct observation periods, with a range of 0 to $100 \%$. All 4 natural lying positions (head back, head up, flat on the side, and head on the ground) were observed in 9 of the bedded packs. In 3 barns, cows did not exhibit a flaton-the-side position during our $8 \mathrm{~h}$ of direct observation. The majority $(84.6 \pm 17.3 \%)$ of cows observed lying down assumed the head-up position. The head-back lying position was assumed in $8.8 \pm 10.8 \%$ of lying events, the head on the ground position in $5.4 \pm 12.0 \%$ of lying events, and the flat on the side position in $0.8 \pm 2.7 \%$ of lying events.

\section{Lying Behavior}

Daily activity data were obtained from 5 to $44 \%$ of the cows in each herd, because some of the monitors malfunctioned during the collection period in 3 dairies. A total of 147 cows and 1,072 cow-days were successfully monitored for daily cow activity with the activity monitors. The daily lying time for all cows was $9.34 \pm$ $1.94 \mathrm{~h}$ (Table 2). The daily lying time for the 2 herds that had access to pasture was $6.45 \pm 1.57 \mathrm{~h}$. In comparison, cows that did not have access to pasture lay down for $9.99 \pm 2.02 \mathrm{~h} / \mathrm{d}$. Lying times of 10 to $14 \mathrm{~h} / \mathrm{d}$ in straw yard loose-housing systems were reported previously (Singh et al., 1993; Fregonesi and Leaver, 2002). Similarly, cows in free stalls were reported to lay down for 9 to 15 h/d (Fregonesi and Leaver, 2002; Cook et al., 2004; Drissler et al., 2005).

It is important to optimize the resting time of dairy cattle to ensure that their welfare and productivity are not compromised (Haley et al., 2001). Metz (1985) found that cows gave up other activities, such as eating or drinking, to lie down after being deprived of lying for $3 \mathrm{~h}$. Munksgaard et al. (2005) observed that lying time had a higher priority than eating or social contact time in early and late lactation. The repeated deprivation of lying is adverse to cows by affecting the natural diurnal rhythm of lying and causing physiological changes that result in abnormal behavior patterns indicative of frustration (Munksgaard and Simonsen, 1996).

Housing facilities can substantially influence the lying activity of dairy cows. Haley et al. (2001) reported that cows on softer flooring lay down for longer times over the entire day; however, the average duration of each individual lying bout was longer when cows were housed on concrete. Cows stood up more frequently and remained standing for shorter periods when housed on softer flooring than on concrete. The authors suggested that cows are more reluctant to stand up and lie down on hard surfaces, such as concrete, because of the discomfort felt when going through the process of standing up and lying down. Compost dairy barns in general have a soft and cushioned lying surface that allows cows to stand up and lie down without apparent discomfort.

The number of lying bouts per day in compost barns was $11.0 \pm 3.2$ (Table 2). We were unable to summarize this information for one of the farms (farm 5); therefore, 11 dairies were used in the analysis. Similarly, Singh et al. (1994) indicated that cows housed in a straw yard lay down 10.3 times/d. Cook et al. (2004) observed 10.3 lying bouts/d for sand and 11.5 lying bouts/d for mattress bedding. Likewise, Drissler et al. (2005) observed 11.4 bouts/d in sand-bedded free stalls. Therefore, the compost dairy barns in this study allowed cows to lie down as many times per day as in other types of housing. 
Table 3. Lactation number, DIM, 305-d mature-equivalent milk production, and their association with lying time and number of lying bouts for 147 cows housed in compost barns

\begin{tabular}{lllc}
\hline Variable & Coefficient & $\mathrm{SE}$ & $P$ \\
\hline Lactation number & & & \\
Lying time, h/d (all herds) & -0.483 & 4.175 & 0.91 \\
Lying bouts, h/d (all herds) & -0.232 & 0.133 & 0.08 \\
Lying time, h/d (without pasture herds) & -2.889 & 4.582 & 0.53 \\
Lying bouts, n/d (without pasture herds) & -0.264 & 0.148 & 0.07 \\
DIM & & & \\
Lying time, h/d (all herds) & 0.331 & 0.071 & 0.001 \\
Lying bouts, h/d (all herds) & 0.0047 & 0.0022 & 0.03 \\
Lying time, h/d (without pasture herds) & 0.369 & 0.079 & 0.02 \\
Lying bouts, n/d (without pasture herds) & 0.0059 & 0.0025 & 0.17 \\
305-d mature-equivalent milk production & & & 0.02 \\
Lying time, h/d (all herds) & 0.0025 & 0.0018 & 0.17 \\
Lying bouts, h/d (all herds) & 0.00012 & 0.00005 & 0.07 \\
Lying time, h/d (without pasture herds) & 0.0026 & 0.0019 & 0.00006 \\
Lying bouts, n/d (without pasture herds) & 0.00010 & & \\
\hline
\end{tabular}

The lying bout duration was $50.8 \pm 35.6 \mathrm{~min}$. The same cow that had only 2 lying bouts in a day also had the longest individual lying bout length of $358 \mathrm{~min}$. No on-farm records were available to help explain the possible cause of the long lying bouts observed for this animal.

As DIM increased, the total number of lying bouts increased ( $P=0.03$; Table 3$)$, corresponding to an increase in total daily lying time $(P<0.001)$. When the 2 farms on which cows had access to pasture were removed from the analysis, similar results were observed, with an increase in the number of lying bouts $(P=0.02)$ and lying time $(P<0.001)$ as DIM increased $(\mathrm{n}=698)$. Similarly, previous research found that the number of lying bouts was greater for early-lactation cows than for those in late lactation (Munksgaard et al., 2005). The number of lying bouts was positively associated with 305-d mature-equivalent milk production $(P=$ 0.02 ) when all farms were included in the analysis. Yet total lying time per day was not associated with 305-d mature-equivalent milk production (Table 3 ). The observed association between DIM and behavior could be related to stage of pregnancy, because cows tended to lie down for longer total times but stood up and lay down more often, perhaps because they had a greater need to change lying position. We caution that the number of observations for milk production, DIM, and parity used in the current study could be considered limited, and cows that were $<30$ DIM were not used in the analysis. Therefore, more research is needed on the relationship between these parameters and lying behavior of dairy cows in compost bedded-pack housing systems.

Cattle housed in compost barns exhibited a significant pattern of temporal cyclicity in their lying behavior, similar to what was observed in other housing systems. The cows spent a greater $(P<0.001)$ amount of time lying at night (2000 to $0800 \mathrm{~h}$ ) than during the day ( 0800 to $2000 \mathrm{~h}$ ). The cows housed in compost barns spent $56.8 \%$ (34 min) of each hour lying down at night, for a total of $6.8 \mathrm{~h}$, compared with $23.1 \%$ (14 min) of each hour lying down during the day, for a total of 2.8 h (Figure 1). Similarly, Dechamps et al. (1989) found that cows housed in cubicles lay down for $8.1 \mathrm{~h}$ during the night and $3.5 \mathrm{~h}$ during the day (divided into 12 -h increments with $0600 \mathrm{~h}$ as the start of day). Additionally, Singh et al. (1994) observed that cows on straw yards lay down for less time during the day $(2.33 \mathrm{~h})$ than during the night $(7.38 \mathrm{~h})$. It appears that cows in compost barns have a similar diurnal pattern of lying behavior.

The greatest percentage of time spent lying was observed at $0300 \mathrm{~h}$, with $76.5 \pm 28.1 \%(45.9 \pm 16.7 \mathrm{~min})$ of the hour spent lying (Figure 1). Peak lying times were observed from 2000 to $0400 \mathrm{~h}$. Similarly, Singh et al. (1994) observed that the maximum number of cows lying down occurred between midnight and 0500 h. Overton et al. (2002) observed a decrease in lying time during the midday, late afternoon, and early evening hours. They found the greatest proportion of eligible cows lying at $0600 \mathrm{~h}(85 \%)$ and the second greatest at $2200 \mathrm{~h}(81 \%)$, both coinciding with $2 \mathrm{~h}$ after milking. The lowest proportion of lying was at $2100 \mathrm{~h}$.

\section{Walking, Standing, and Active Behavior}

Standing time was $13.22 \pm 2.19 \mathrm{~h} / \mathrm{d}$ (range of 4.12 to $20.26 \mathrm{~h} / \mathrm{d}$ ). Peak standing times were from 1100 to 1900 $\mathrm{h}$. The greatest percentage of time spent standing was at $1700 \mathrm{~h}$, with $78.3 \pm 26.5 \%(47.0 \pm 15.9 \mathrm{~min})$ of the hour spent standing. A majority of the herds were being milked during this hour. The peak number of steps occurred at $1800 \mathrm{~h}$, with an average of $163 \pm 120$ steps taken for all cows monitored on all farms. The least number of steps occurred between 2000 and $0400 \mathrm{~h}$, 


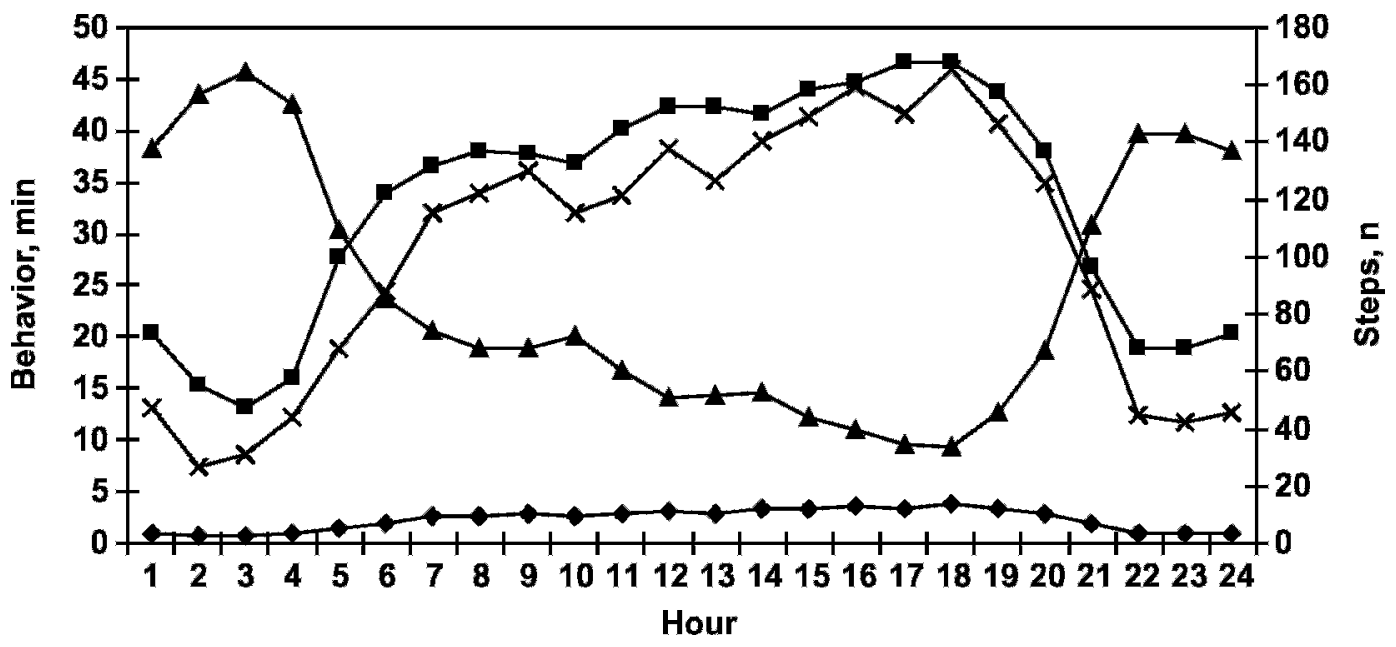

Figure 1. Number of minutes each hour of the day (h $1=0100$ h, h $24=2400$ h) spent standing ( $\square$ ), lying ( $\mathbf{\Delta})$, and active ( $\bullet$ ), and the average number of steps $(\times)$ taken each hour for 25,734 hourly observations of 147 cows housed in compost dairy barns.

corresponding to the hours of increased lying activity (Figure 1).

The peak amount of active behavior for all cows in compost barns was recorded at $1600 \mathrm{~h}$, with $6.2 \pm 5.3 \%$ $(3.7 \pm 3.2 \mathrm{~min})$ of the hour spent active (Figure 1$)$. The least amount of this behavior was recorded at $0300 \mathrm{~h}$, with $1.0 \pm 1.7 \%(0.6 \pm 1.0 \mathrm{~min})$ of the hour spent active. The 2200 - to 0400 -h period was the time cows were the least active. The 23 cows monitored on the 2 farms with pasture access spent a greater amount of time being active, with $8.6 \%$ (5.2 min) of each hour spent performing an active behavior, whereas the remaining 124 cows spent an average of $2.9 \%$ (1.7 min) of each hour being active. This can be attributed to the greater amount of time spent grazing (when cows may stand in one place but continue to move their legs without taking a step) or possibly to greater fly pressure when on pasture.

\section{THI and Lying Behavior}

Lying behavior had an inverse relationship with the THI during the monitoring period $(\mathrm{n}=25,734)$. Cows in the compost barns lay down fewer minutes per hour $(P<0.001)$ as the THI increased (coefficient -0.44 ; SE $0.028)$. The length of lying bouts decreased $(-0.80 ; 0.03)$ as the THI increased $(P<0.001)$, whereas the number of lying bouts was not associated with the THI. Additionally, cows increased $(P<0.001)$ the number of steps taken as the THI increased $(0.16 ; 0.08)$. Similar results were observed when the 2 farms on which cows had access to pasture were excluded from the analysis ( $\mathrm{n}=$ $22,136)$. These changes in behavior could be an indication of restlessness or stress, or a greater need to walk to the water trough during warmer periods.
We compared lying time when the THI was $\geq 72$ (60\% of all hourly observations) or $<72$ (40\% of all hourly observations) during the entire study period (Table 4). Arnold and Dudzinski (1978) reported a THI of 72 as the point of initial heat stress in dairy cattle. The time lying per hour was $53.6 \pm 38.5 \%$, or $12.7 \mathrm{~h} / \mathrm{d}$, when the THI was $<72$. In contrast, the time lying per hour was $32.8 \pm 37.1 \%$, or $7.9 \mathrm{~h} / \mathrm{d}$, when the THI was $\geq 72$. Therefore, less time $(P<0.001)$ was spent lying when the THI was $\geq 72$. Overton et al. (2002) found that high environmental temperatures had a negative impact on the proportion of eligible cows observed lying. This relationship seems similar for cows housed in compost dairy barns, emphasizing the importance of heat abatement in dairy cow facilities to improve cow comfort and optimize productivity.

Table 4. Behavior of dairy cows housed in 12 compost dairy barns at 2 temperature-humidity indexes (THI)

\begin{tabular}{lccccc}
\hline & \multicolumn{2}{c}{ Lying time, h/d } & & \multicolumn{2}{c}{ Steps, $\mathrm{n} / \mathrm{h}$} \\
\cline { 2 - 3 } \cline { 5 - 6 } Farm & THI $<72$ & THI $\geq 72$ & & THI $<72$ & THI $\geq 72$ \\
\hline 1 & 14.04 & 10.06 & & 44.8 & 76.3 \\
$2^{1}$ & 6.98 & 6.42 & & 150.9 & 234.3 \\
$3^{1}$ & 14.80 & 5.47 & & 103.8 & 271.2 \\
4 & 16.20 & 8.28 & & 57.4 & 104.7 \\
6 & 13.04 & 7.94 & & 66.1 & 90.3 \\
7 & 11.56 & 7.85 & & 70.2 & 91.5 \\
8 & 12.76 & 10.23 & & 60.7 & 70.8 \\
9 & 14.86 & 6.92 & & 64.3 & 112.2 \\
10 & 12.85 & 6.18 & & 62.5 & 97.3 \\
11 & 12.77 & 7.87 & & 60.7 & 79.4 \\
12 & 12.16 & 5.86 & & 73.7 & 111.2 \\
Mean & 12.70 & 7.90 & 71.6 & 120.8 \\
SD & 9.22 & 8.93 & 29.2 & 63.6 \\
\hline
\end{tabular}

${ }^{1}$ Herd with access to pasture. 


\section{Social Behavior}

Cows were able to move freely on the bedded pack. We made various observations of cows running in the pack and standing in estrus. A total of 96 continuous hourly observations of social interactions were recorded. The mean of $0.94 \pm 1.5$ occurrences of chasing away were recorded (range of 0 to 8 observations) during a single hour. Pushing occurred $0.94 \pm 1.8$ times/ $\mathrm{h}$ (range of 0 to 11 observations). The third agonistic interaction recorded was head butting, with $1.4 \pm 1.6$ incidences/h (range of 0 to 9 observations). The positive social interaction of allogrooming, or social licking, was recorded $2.3 \pm 2.9$ times/h (range of 0 to 13 observations). Miller and Wood-Gush (1991) reported that the number of agonistic behaviors of cows housed indoors in cubicles was greater $(9.5 / \mathrm{h})$ than those of cows on pasture $(1.1 / \mathrm{h})$. Although those authors included other types of agonistic interactions in their study, such as avoidance and threat postures, the number of agonistic behaviors observed on pasture was similar to the number we observed in the current study. When recording social interactions in the cubicle housing, Miller and Wood-Gush (1991) observed cows in the feed alley, where $67 \%$ of the agonistic interactions occurred, whereas we observed the behavior of cows only in the bedded-pack (resting) area. Krohn (1994) observed 5 to 6 times fewer aggressive interactions between cows on pasture than between cows housed in tie stalls, concrete yards, or bedded packs $\left(7 \mathrm{~m}^{2} / \mathrm{cow}\right)$. Nevertheless, Fregonesi and Leaver (2001) observed that cows had a similar number of aggressive interactions in free-stall housing as on pasture when the same total space allowance was available. The social interactions of cows in the compost barns did not differ substantially from those in previous reports on cow social behavior in other types of housing, adding to the conclusion that compost dairy barns can be an adequate system for housing lactating cows.

\section{CONCLUSIONS}

Cows in the compost barns lay down less time daily and had shorter lying bouts as the THI increased. In addition, cows increased the number of steps taken as the THI increased, which is perhaps an indication of restlessness and stress. These results add to the body of literature on the importance of heat abatement in dairy cattle facilities to optimize health and productivity. Observations of lying behavior, social interactions, and natural lying positions indicate that compost dairy barns can be an adequate housing system for dairy cows, because these observations were not substantially different from those previously reported with other types of housing.

\section{ACKNOWLEDGMENTS}

We would like to thank the dairy producers for their participation and support. We thank the extension educators, Vince Crary, Jim Salfer, and Wayne Schoper, who helped identify cooperating producers. We thank Stanford Weisberg and his staff for their statistical expertise and advice. We are grateful to Luis Espejo for his help with data analysis and to Jim Salfer for his help with collection of DHIA data.

\section{REFERENCES}

Arnold, G. W., and M. L. Dudzinski. 1978. Ethology of free-ranging domestic animals. G. W. Arnold and M. L. Dudzinski, ed. Elsevier, Amsterdam, the Netherlands.

Barberg, A. E., M. I. Endres, J. A. Salfer, and J. K. Reneau. 2007. Performance, health and well-being of dairy cows in an alternative housing system in Minnesota. J. Dairy Sci. 90:1575-1583.

Ceballos, A., D. Sanderson, J. Rushen, and D. M. Weary. 2004. Improving stall design: Use of 3-D kinematics to measure space use by dairy cows when lying down. J. Dairy Sci. 87:2042-2050.

Cook, N. B., T. B. Bennett, and K. V. Nordlund. 2004. Effect of free stall surface on daily activity patterns in dairy cows with relevance to lameness prevalence. J. Dairy Sci. 87:2912-2922.

Dechamps, P., B. Nicks, B. Canart, M. Gielen, and L. Istasse. 1989. A note on resting behaviour of cows before and after calving in two different housing systems. Appl. Anim. Behav. Sci. 23:99-105.

Drissler, M., M. Gaworski, C. B. Tucker, and D. M. Weary. 2005. Freestall maintenance: Effects on lying behavior of dairy cattle. J. Dairy Sci. 88:2381-2387.

Fregonesi, J. A., and J. D. Leaver. 2001. Behaviour, performance and health indicators of welfare for dairy cows housed in strawyard or cubicle systems. Livest. Prod. Sci. 68:205-216.

Fregonesi, J. A., and J. D. Leaver. 2002. Influence of space allowance and milk yield level on behaviour, performance and health of dairy cows housed in strawyard and cubicle systems. Livest. Prod. Sci. 78:245-257.

Haley, D. B., A. M. De Passille, and J. Rushen. 2001. Assessing cow comfort: Effects of two floor types and two tie stall designs on the behaviour of lactating dairy cows. Appl. Anim. Behav. Sci. 71:105-117.

Ketelaar-de Lauwere, C. C., A. H. Ipema, E. N. J. v. Ouwerkerk, M. M. W. B. Hendriks, J. H. M. Metz, J. P. T. M. Noordhuizen, and W. G. P. Schouten. 1999. Voluntary automatic milking in combination with grazing of dairy cows: Milking frequency and effects on behaviour. Appl. Anim. Behav. Sci. 64:91-109.

Krohn, C. C. 1994. Behaviour of dairy cows kept in extensive (loose housing/pasture) or intensive (tie stall) environments. III. Grooming, exploration and abnormal behaviour. Appl. Anim. Behav. Sci. 42:73-86.

Krohn, C. C., and L. Munksgaard. 1993. Behaviour of dairy cows kept in extensive (loose housing/pasture) or intensive (tie stall) environments. II. Lying and lying-down behaviour. Appl. Anim. Behav. Sci. 37:1-16.

Menke, C., S. Waiblinger, D. W. Folsch, and P. R. Wiepkema. 1999. Social behaviour and injuries of horned cows in loose housing systems. Anim. Welf. 8:243-258.

Metz, J. H. 1985. The reaction of cows to a short-term deprivation of lying. Appl. Anim. Behav. Sci. 13:301-307.

Miller, K., and D. G. M. Wood-Gush. 1991. Some effects of housing on the social behavior of dairy cows. Anim. Prod. 53:271-278.

Munksgaard, L., M. B. Jensen, L. J. Pedersen, S. W. Hansen, and L. Matthews. 2005. Quantifying behavioural priorities - Effects of time constraints on behaviour of dairy cows, Bos taurus. Appl. Anim. Behav. Sci. 92:3-14.

Munksgaard, L., C. G. Reenen, and R. Boyce. 2006. Automatic monitoring of lying, standing, and walking behavior in dairy cattle. J. Dairy Sci. 89(Suppl. 1):309. (Abstr.) 
Munksgaard, L., and H. B. Simonsen. 1996. Behavioral and pituitary adrenal-axis responses of dairy cows to social isolation and deprivation of lying down. J. Anim. Sci. 74:769-778.

Overton, M. W., W. M. Sischo, G. D. Temple, and D. A. Moore. 2002. Using time lapse video photography to assess dairy cattle lying behavior in a free stall barn. J. Dairy Sci. 85:2407-2413.

Singh, S. S., W. R. Ward, J. W. Hughes, K. Lautenbach, and R. D. Murray. 1994. Behaviour of dairy cows in a straw yard in relation to lameness. Vet. Rec. 135:251-253.
Singh, S. S., W. R. Ward, K. Lautenbach, and R. D. Murray. 1993. Behaviour of lame and normal dairy cows in cubicles and in a straw yard. Vet. Rec. 133:204-208.

Sprecher, D. J., D. E. Hostetler, and J. B. Kaneene. 1997. A lameness scoring system that uses posture and gait to predict dairy cattle reproductive performance. Theriogenology 47:1179-1187.

West, J. W., B. G. Mullinix, and J. K. Bernard. 2003. Effects of hot, humid weather on milk temperature, dry matter intake, and milk yield of lactating dairy cows. J. Dairy Sci. 86:232-242. 